\title{
Contributions of Residual Calcium to Fast Synaptic Transmission
}

\author{
Chinfei Chen and Wade G. Regehr \\ Department of Neurobiology, Harvard Medical School, Boston, Massachusetts 02115
}

Fast neurotransmitter release is driven by high calcium (10-100 $\mu \mathrm{M})$ near open channels $\left(\mathrm{Ca}_{\text {local }}\right)$, followed by a much smaller $(<1 \mu \mathrm{M})$, longer-lasting residual calcium $\left(\mathrm{Ca}_{\text {res }}\right)$. The most prominent component of release, phasic release, lasts several milliseconds and is thought to be triggered by $\mathrm{Ca}_{\text {local. }}$. A transient tail of release then continues over the next $20 \mathrm{msec}$ at $1-10 \%$ of peak rates. This transient component of release, which we refer to as TR, is poorly understood, and there is conflicting evidence regarding the role of $\mathrm{Ca}_{\text {local }}$ and $\mathrm{Ca}_{\text {res }}$ in its generation. We used optical methods to monitor $\mathrm{Ca}_{\text {res }}$ and whole-cell voltage-clamp recordings to study TR at synapses between granule cells and stellate cells in rat cerebellar slices. After stimulation the probability of release is elevated greatly, peaking at $500 \mu \mathrm{sec}$ and then slowly declining to prestimulus levels after tens of milliseconds. After speeding the decay of $\mathrm{Ca}_{\text {res }}$ levels with EGTA, release is confined to a $3 \mathrm{msec}$ interval, and TR is eliminated. Thus, we find that $\mathrm{Ca}_{\text {res }}$ accounts for $\mathrm{a}$ transient tail of release on the millisecond time scale that helps to shape the average synaptic current and accounts for at least $20 \%$ of the synaptic charge in the 20 msec interval after stimulation. $\mathrm{Ca}_{\text {res }}$-dependent TR is likely to contribute significantly to fast synaptic transmission under physiological conditions, particularly during high-frequency bursts that elevate $\mathrm{Ca}_{\text {res }}$.

Key words: phasic release; delayed release; synaptic transmission; residual calcium; EPSC time course; cerebellum; granule cell; stellate cell
After action potential invasion, peak rates of neurotransmitter release are often $>10^{5}$ times the basal rates of spontaneous release (Magleby, 1987) and last only several milliseconds; this component of release often is referred to as phasic release. By tens to hundreds of milliseconds after action potential invasion, release still continues but at a much lower rate, typically $0.01-1 \%$ of peak rates. Such prolonged release is known as delayed release (DR) (Miledi and Thies, 1971; Barrett and Stevens, 1972; Rahamimoff and Yaari, 1973; Zucker and Lara-Estrella, 1983; Cohen and Van der Kloot, 1986; Van der Kloot and Molgo, 1994). At intermediate times the release rates are $1-10 \%$ of peak rates; for convenience we will refer to this phase of release (from 3 to 20 msec after the onset of release) as transient release (TR). TR helps to shape the EPSC (Van der Kloot, 1988) and contributes to a significant fraction of the total synaptic charge delivered to a postsynaptic cell, thereby prolonging the influence of a presynaptic cell on the firing of its targets. Although TR has been observed at many types of synapses (Katz and Miledi, 1964, 1965; Diamond and Jahr, 1995; Isaacson and Walmsley, 1995), the factors governing this component of release remain poorly understood.

To determine the mechanism underlying TR, we focused on the possible role of presynaptic calcium. When an action potential invades a presynaptic bouton, it opens calcium channels, giving rise to a locally high calcium signal $(10-100 \mu \mathrm{M})$ near open channels $\left(\mathrm{Ca}_{\text {local }}\right)$ (Chad and Eckert, 1984; Fogelson and Zucker, 1985; Simon and Llinás, 1985; Roberts et al., 1990; Matthews, 1996). As the calcium equilibrates throughout the bouton, a much

\footnotetext{
Received April 2, 1999; revised May 10, 1999; accepted May 11, 1999.

This work was supported by National Institutes of Health Grant R01-NS32405-01 and by the Howard Hughes Physician Postdoctoral Fellowship and National Institutes of Health Grant K08 NS02056-01 to C.C. We thank B. Bean, A. Carter, K. Delaney, J. Dittman, D. Finley, A. Kreitzer, J.-W. Lin, G. Yellen, M. Xu-Friedman, and R. Zucker for comments on this manuscript.

Correspondence should be addressed to Dr. Wade G. Regehr, Department of Neurobiology, Harvard Medical School, 220 Longwood Avenue, Boston, MA 02115. Copyright (C) 1999 Society for Neuroscience $0270-6474 / 99 / 196257-10 \$ 05.00 / 0$
}

smaller $(<1 \mu \mathrm{M})$, longer-lasting residual calcium signal persists $\left(\mathrm{Ca}_{\text {res}}\right)$ (Delaney et al., 1989; Regehr and Atluri, 1995; Feller et al., 1996; Helmchen et al., 1997; Ravin et al., 1997). It has been shown that phasic release is triggered by $\mathrm{Ca}_{\text {local }}$ (Adler et al., 1991; Schweizer et al., 1995; Matthews, 1996), whereas delayed release is driven by $\mathrm{Ca}_{\text {res }}$ (Delaney et al., 1989; Van der Kloot and Molgo, 1993; Cummings et al., 1996; Ravin et al., 1997; Atluri and Regehr, 1998). However, the relationship between presynaptic calcium and TR is unclear. Two mechanisms involving presynaptic calcium could account for TR. The first possibility is that TR is primarily a reflection of a calcium-dependent process with slow kinetics driven by $\mathrm{Ca}_{\text {local }}$, with no $\mathrm{Ca}_{\text {res }}$ contribution. The alternative possibility is that $\mathrm{Ca}_{\text {res }}$ contributes to $\mathrm{TR}$ in the same manner that it drives DR.

There is conflicting evidence regarding the role of $\mathrm{Ca}_{\text {res }}$ in TR. Arguments against $\mathrm{Ca}_{\text {res }}$ involvement emphasize the difficulty in reconciling the known calcium dependence of release with a role for $\mathrm{Ca}_{\text {res }}$. In granule cells several milliseconds after action potential invasion, $\mathrm{Ca}_{\text {res }}$ levels are only a few hundred nanomolars (Regehr and Atluri, 1995), which is well below the 10-100 $\mu \mathrm{M}$ threshold thought to be required to obtain significant rates of release (Fogelson and Zucker, 1985; Simon and Llinás, 1985; Roberts et al., 1990; Heidelberger et al., 1994). Furthermore, the rates of DR after single stimuli are typically thousands of times smaller than peak release rates. These results suggest that $\mathrm{Ca}_{\text {res }}{ }^{-}$ driven release may not contribute significantly to the EPSC. On the other hand, recent observations support a possible role for $\mathrm{Ca}_{\text {res }}$ in TR. Introduction of relatively low concentrations of the slow calcium chelator EGTA, which affects $\mathrm{Ca}_{\text {res }}$ much more than $\mathrm{Ca}_{\text {local }}$, reduces phasic neurotransmitter release at the calyx of Held (Borst and Sakmann, 1996). Moreover, our previous studies suggest that accelerating $\mathrm{Ca}_{\text {res }}$ decay may speed the decay of synaptic currents (Atluri and Regehr, 1998). These observations suggest $\mathrm{Ca}_{\text {res }}$ may play a role in TR.

Although it has been proposed previously that $\mathrm{Ca}_{\text {res }}$ could 
Figure 1. EGTA-AM accelerates the decay of $\mathrm{Ca}_{\text {res }}$ and affects the EPSC. $A$, Peak amplitudes ( filled circles) and halfdecay times (open circles) of magnesium green fluorescence $(\Delta F / F)$ transients were monitored during the addition of $100 \mu \mathrm{M}$ EGTA-AM into the bath solution (left). Time 0 indicates the onset of EGTA application (black bar). Average calcium transients before (thin trace) and after (bold trace) loading with EGTA are superimposed in the right. Each trace is the average of 20 trials. $B$, Left, The time course of the peak EPSC during bath exposure to $100 \mu \mathrm{M}$ EGTAAM. Each point represents the average value of 10 consecutive peak measurements. B, Right, Superimposed average current traces are shown before (thin trace) and after (bold trace) EGTA application. The synaptic currents are normalized to their respective peak amplitude in the far right to demonstrate the acceleration of the time course of the EPSC waveform after exposure to EGTA. Calcium measurements $(A)$ and synaptic currents $(B)$ were obtained from two different experiments.
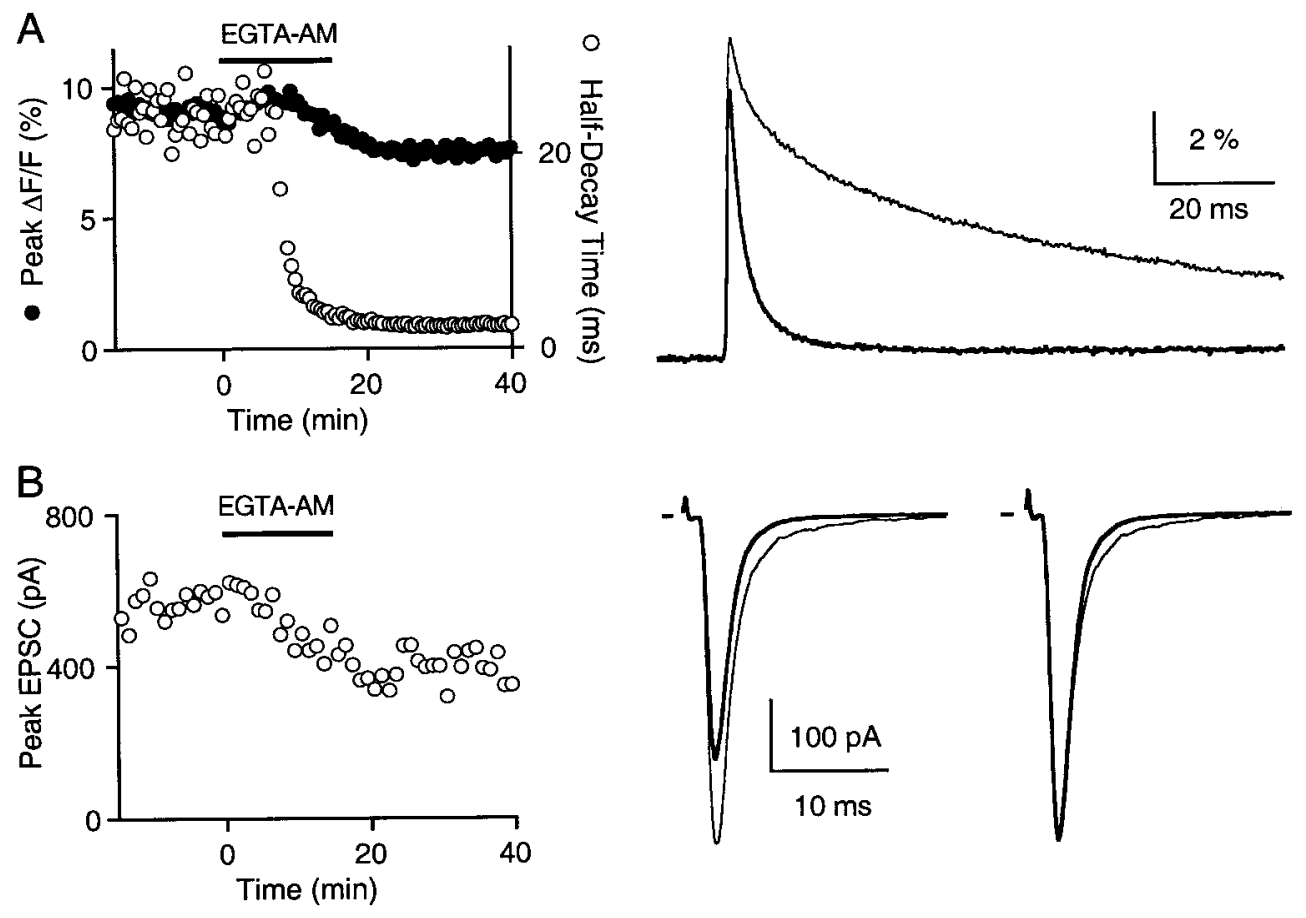

contribute to release on rapid time scales, there is little direct information on the contribution of $\mathrm{Ca}_{\text {res }}$ to TR (Magleby, 1987). Most previous studies have focused on the hundreds of milliseconds to seconds after brief trains of presynaptic activity (Hubbard, 1963; Miledi and Thies, 1971; Erulkar and Rahamimoff, 1978; Zengel and Magleby, 1981; Zucker and Lara-Estrella, 1983; Ravin et al., 1997). DR also has been examined after single stimuli, but typically these studies focused on longer time scales and were not designed to provide information on the tens of milliseconds time scale (Barrett and Stevens, 1972; Van der Kloot and Molgo, 1993; Goda and Stevens, 1994; Atluri and Regehr, 1998).

We tested the involvement of $\mathrm{Ca}_{\text {res }}$ in $\mathrm{TR}$ at synapses between granule cells and stellate cells in rat cerebellar slices. By using low stimulus intensities, we were able to detect quantal events and determine the release probability as a function of time after stimulation. In response to low-frequency stimulation the probability of release is elevated transiently, peaks $500 \mu$ sec later, and then slowly declines to prestimulus levels. After speeding the decay of $\mathrm{Ca}_{\text {res }}$, release was confined to a $3 \mathrm{msec}$ interval, and later release events were eliminated. These results indicate that $\mathrm{Ca}_{\text {res }}{ }^{-}$ sensitive release helps to shape the EPSC and contributes a significant fraction of the total synaptic charge.

\section{MATERIALS AND METHODS}

Electrophysiology. Transverse slices $(300 \mu \mathrm{m})$ from the cerebellar vermis of postnatal day (P) P14-P19 rats (Harlan, Indianapolis, IN) were cut as described previously (Konnerth et al., 1990; Atluri and Regehr, 1998). Slices were maintained in an oxygenated $\left(95 \% \mathrm{O}_{2} / 5 \% \mathrm{CO}_{2}\right)$ external solution containing (in mM): $125 \mathrm{NaCl}, 2.5 \mathrm{KCl}, 2.6 \mathrm{NaHCO}_{3}, 1.25$ $\mathrm{NaH}_{2} \mathrm{PO}_{4}, 25$ glucose, $2 \mathrm{CaCl}_{2}$, and $1 \mathrm{MgCl}_{2}$. The external recording solution also contained $20 \mu \mathrm{M}$ bicuculline (Sigma, St. Louis, MO) and $100 \mu \mathrm{M}$ AP5 (2-amino-5-phosphonopentanoic acid; Research Biochemicals, Natick, MA). In experiments involving low calcium, the external solution contained $1 \mathrm{~mm} \mathrm{Ca}$ and $2 \mathrm{~mm} \mathrm{Mg}$. EGTA-acetoxymethyl ester (AM; Molecular Probes, Eugene, OR) was dissolved in dimethyl sulfoxide (DMSO) and used as previously described (Atluri and Regehr, 1996). The $0.1 \%$ DMSO does not affect evoked or spontaneous miniature EPSCs (mEPSCs) (Atluri and Regehr, 1996). Furthermore, cleavage of the acetoxymethyl ester, alone, does not affect synaptic transmission, because visibly labeling a slice with BCECF-AM (100 $\mu \mathrm{M}$ for $20 \mathrm{~min})$, a dye that does not bind calcium, does not alter the time course of release $(n=3$; data not shown). Whole-cell patch-clamp recordings of stellate cells (2-2.5 M $\Omega$ electrodes) were obtained under visual guidance (Atluri and Regehr, 1998). The internal solution contained (in mM): $35 \mathrm{CsF}, 100$ $\mathrm{CsCl}, 10$ EGTA, 10 HEPES, and 0.1 D600, pH 7.4. Parallel fibers were stimulated with two glass electrodes placed in the molecular layer several hundred micrometers from the recording electrode. The intervals between evoked trials ( 6 and $2 \mathrm{sec}$ for experiments at 24 and $34^{\circ} \mathrm{C}$, respectively) did not facilitate synaptic currents. In the experiments of Figure 1 the stimulus intensity was maintained at the same amplitude. In all other experiments our goal was to detect individual quantal events; therefore, the stimulus intensity was adjusted such that $30-50 \%$ of the trials were failures and, on average, $0.5-1.5$ quanta were evoked per trial. EPSCs were measured at $-70 \mathrm{mV}$.

Data analysis. Stimulus-evoked currents were filtered at $5 \mathrm{kHz}$ with a four-pole Bessel filter and digitized at $20-50 \mathrm{kHz}$. Quantal events were detected and analyzed off-line with IGOR PRO software (WaveMetrics, Lake Oswego, OR) and custom macros. Then the first and second derivatives were computed, and quanta were detected on the basis of threshold crossings of first and/or second derivatives. The second derivative provides a more reliable means of detecting two closely spaced events but is also more sensitive to noise and to changes in the quality of the recording. Thus, experiments in which the access changed appreciably during the course of the experiment were found to be unreliable with regard to mEPSC detection and were not included for analysis. We estimate that $>90 \%$ of all evoked quanta are detected in our experiments at $24^{\circ} \mathrm{C}$ on the basis of (1) our small number of events per trial, (2) manual inspection, and (3) comparisons of average EPSCs and probability histograms convolved with the average waveform of the quantal events.

Average quantal events were determined from the trials in which only a single event was detected. These events were aligned on the basis of the peak of their second or their first derivative and then used to compute the average quantal event, as in Figure $2 B$. The average failure (events in which there was no quantal event) was used to correct evoked synaptic currents to eliminate the stimulus artifact and prespike. Bin size in all probability histograms is $100 \mu \mathrm{sec}$.

Measurement of $\mathrm{Ca}_{\text {res. }}$. Presynaptic boutons of the cerebellar granule cells were labeled with magnesium green-AM (Molecular Probes), as previously described (Regehr and Tank, 1991; Regehr and Atluri, 1995). Briefly, a local application of a magnesium green-AM solution was delivered to a small region of the molecular layer. The dye was taken up 
A
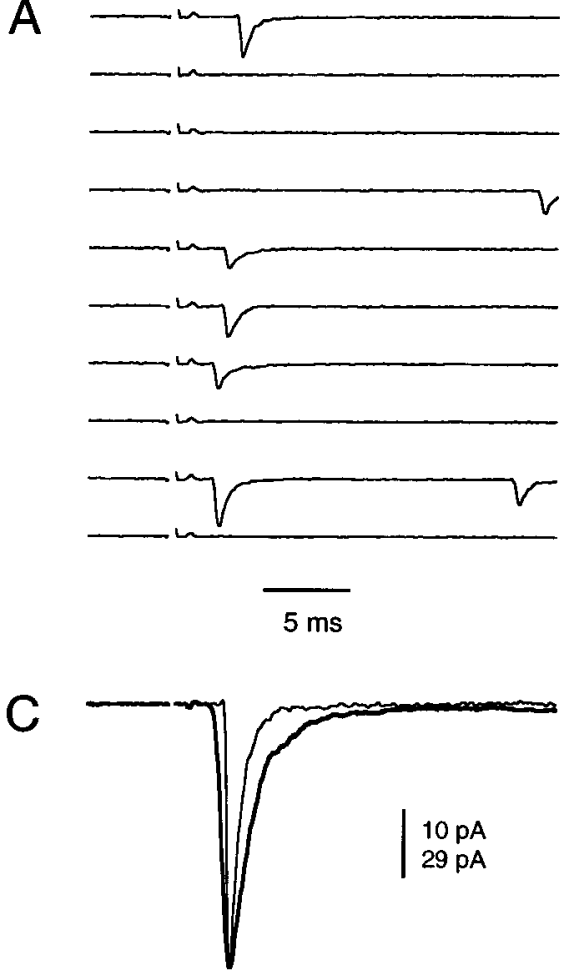
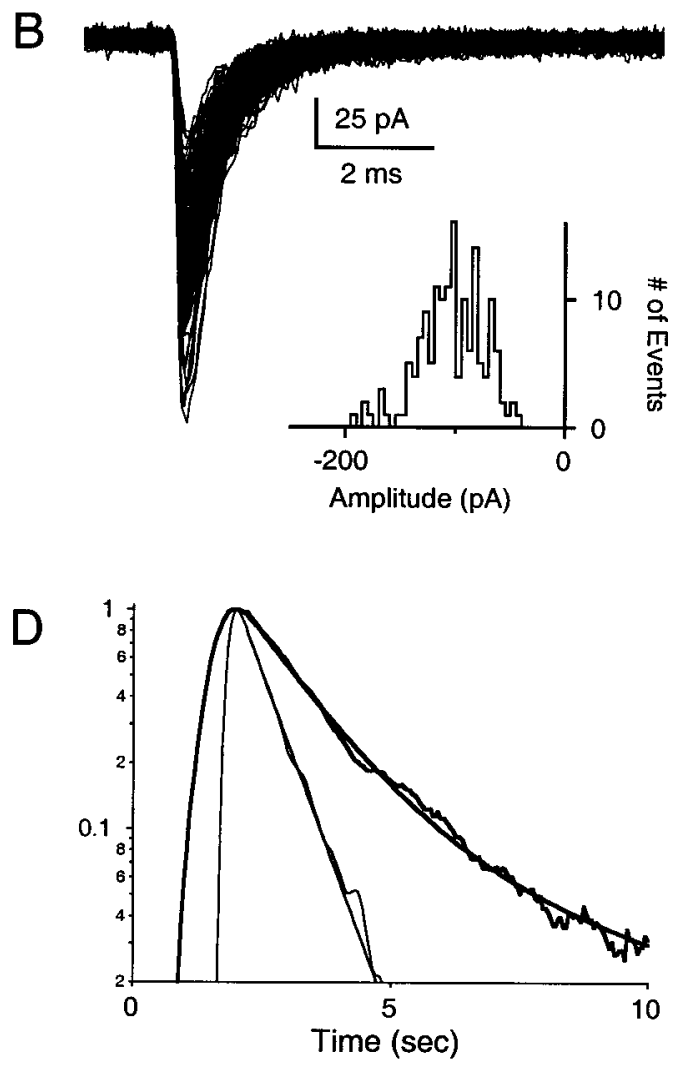

Figure 2. The quantal events underlying the evoked EPSC. $A$, Ten consecutive trials showing representative responses to low-intensity stimulation at $0.17 \mathrm{~Hz}$. Traces have been displaced by $200 \mathrm{pA}$. $B$, Superimposed quantal events (153) that were used to determine the average quantal event. Inset, Amplitude histogram of the quantal events. Detection of the quantal events is described in Materials and Methods. $C$, The average EPSC produced by low-intensity parallel fiber stimulation (bold trace; 873 trials, $0.17 \mathrm{~Hz}$ ). The average response (computed as described in Materials and Methods) is aligned to the peak of the average evoked quantal event (thin trace). The time scale in $A$ and $C$ is the same. The scale bar corresponds to 10 $\mathrm{pA}$ for the average synaptic current and to 29 pA for the average quantal event. $D$, Normalized traces of the evoked EPSC (bold) and average quantal response (thin) are inverted and plotted on a semilogarithmic scale to compare their time courses of decay. The average quantal event is larger than the average EPSC because of failures and asynchrony. by cells in the load site and diffused down the parallel fibers into the presynaptic boutons of the cerebellar granule cells over 1-2 hr. Fluorescence was measured from a 50-70 $\mu \mathrm{m}$ spot size-positioned $400-700 \mu \mathrm{m}$ away from the load site to avoid contaminating signals from the dendritic processes of other cells at the load site. Because, by volume, the parallel fibers consist almost entirely of presynaptic boutons (Palay and ChanPalay, 1974), this fluorescence measurement provides an aggregate measure of the response of many synchronously activated boutons.

The photodiode used in these measurements responded to step changes in intensity with a time constant of $50 \mu \mathrm{sec}$. Signals were filtered at $10 \mathrm{kHz}$ with an eight-pole Bessel filter and digitized at $50 \mathrm{kHz}$. The fluorescence filter set used for magnesium green was 450-490 nm excitation, FT510 dichroic, and LP520 emission. The stimulus intensity was not changed during optical experiments.

\section{RESULTS}

The timing of fast neurotransmitter release was examined at synapses between granule cells and stellate cells in rat cerebellar slices. This preparation offers several advantages: (1) in the presence of bicuculline there is no recurrent excitation or inhibition of local circuits (Palay and Chan-Palay, 1974); (2) stellate cells are small, electrically compact, and readily voltage-clamped (Barbour et al., 1994); (3) mEPSCs are large, rapid, and easily detected; (4) evoked EPSCs can be studied with minimal interference from spontaneous mEPSCs, which occur at very low frequency; and (5) it is possible to detect presynaptic calcium transients from granule cell parallel fibers.

To determine whether the quantal events that underlie the fast EPSC depend on residual presynaptic calcium levels $\left(\mathrm{Ca}_{\mathrm{res}}\right)$, we used EGTA to manipulate $\mathrm{Ca}_{\text {res }}$. Introducing EGTA into presynaptic terminals is an ideal way of perturbing $\mathrm{Ca}_{\text {res }}$ (Adler et al., 1991; Swandulla et al., 1991; Winslow et al., 1994; Atluri and Regehr, 1996, 1998; Naraghi and Neher, 1997). EGTA has little effect on $\mathrm{Ca}_{\text {local }}$ because it binds calcium slowly (Smith et al., 1984). However, because of its high affinity, it binds calcium effectively on longer time scales, thereby speeding the decay of $\mathrm{Ca}_{\text {res. }}$. These properties of calcium binding have established EGTA as an important tool in the study of calcium in synaptic transmission and have allowed us virtually to eliminate $\mathrm{Ca}_{\text {res }}$ while minimally perturbing $\mathrm{Ca}_{\text {local }}$. Previously, we have used EGTA to examine DR and facilitation at this synapse (Atluri and Regehr, 1998).

An example of the effect of EGTA on $\mathrm{Ca}_{\text {res }}$ is shown in Figure $1 A$. To monitor $\mathrm{Ca}_{\text {res }}$, we loaded granule cell terminals with the low-affinity calcium-sensitive fluorophore, magnesium green (Atluri and Regehr, 1996; Zhao et al., 1996). Because granule cell presynaptic boutons are small $(<1 \mu \mathrm{m}$ in diameter), calcium gradients dissipate rapidly (Palay and Chan-Palay, 1974; Sabatini and Regehr, 1998). Therefore, several milliseconds after stimulation the normalized changes in magnesium green fluorescence $(\Delta F / F)$ provide a good estimate of $\mathrm{Ca}_{\text {res }}$ dynamics (Atluri and Regehr, 1996, 1998). In control conditions a single stimulus increases $\mathrm{Ca}_{\text {res }}$ within milliseconds, and then $\mathrm{Ca}_{\text {res }}$ returns to resting levels in several hundred milliseconds (Fig. 1A, right). After the cerebellar slice is exposed to a membrane-permeant form of EGTA (EGTA-AM; $100 \mu \mathrm{M}$ ), presynaptic magnesium green $\Delta F / F$ signals decay rapidly (a half-decay time of $1.8 \mathrm{msec}$ as compared with $24 \mathrm{msec}$ for control), whereas peak $\Delta F / F$ signals are reduced only slightly ( $16 \%$ reduction). Although these fluorescence measurements do not allow us to measure $\mathrm{Ca}_{\text {local }}$, the reduction in peak $\Delta F / F$ (reduced by $16 \pm 2 \% ; n=5$ ) provides an upper bound of the effect of EGTA on $\mathrm{Ca}_{\text {local }}$ (Winslow et al., 1994).

Manipulation of presynaptic calcium transients with EGTA-AM also affects evoked synaptic currents. The application of $100 \mu \mathrm{M}$ EGTA-AM decreased the amplitude of the evoked synaptic current by $26 \%$ (Fig. $1 B$ ). The average reduction in 
A
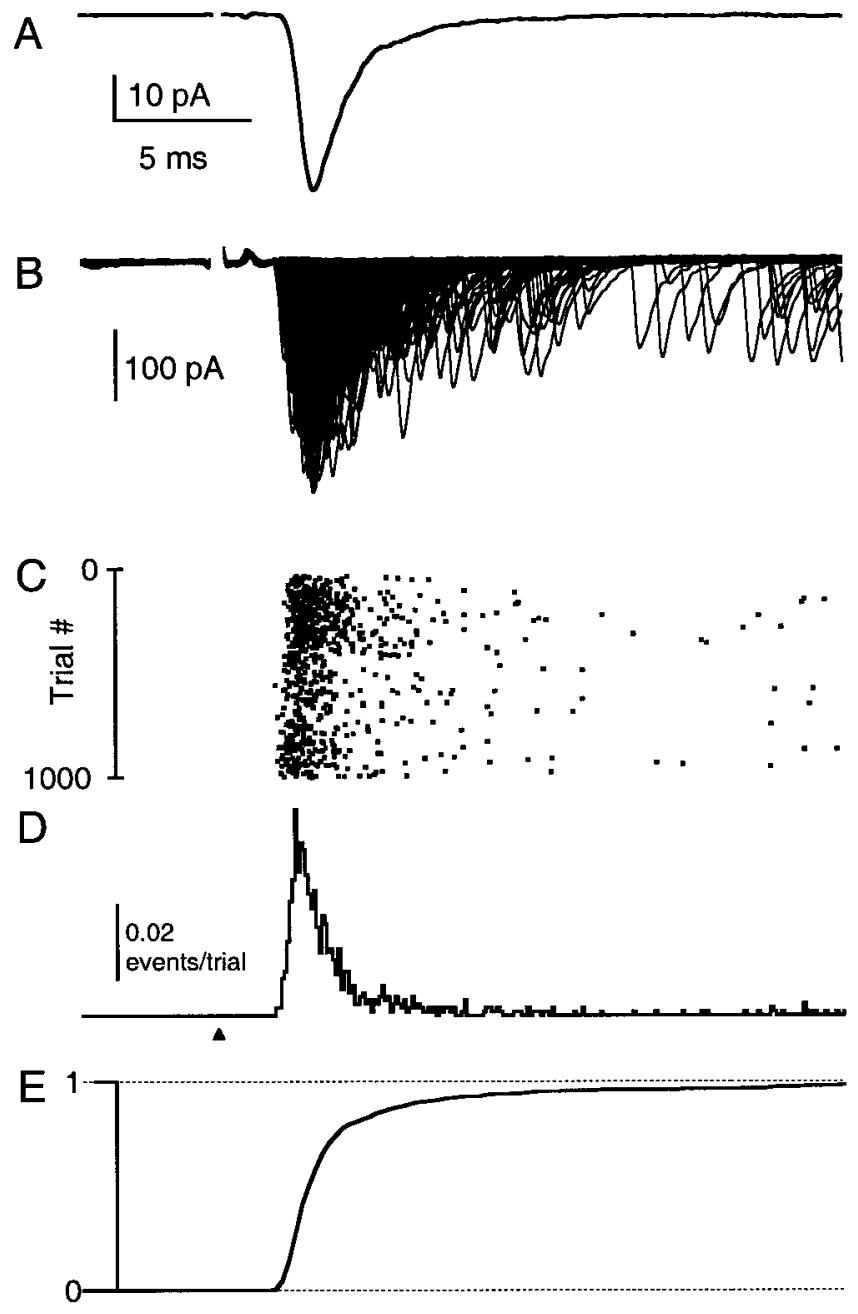

Figure 3. Determination of the time course of release probability. Shown are superimposed traces of the 873 consecutive trials $(B)$ that contribute to the average EPSC $(A)$. Same experiment as in Figure 2. Raster plot of the latency of detected quantal events for each trial $(C)$, corresponding latency histogram $(D)$, and the cumulative latency histogram $(E)$. All traces are plotted on the same time scale and aligned to the time of stimulation (arrowhead). Stimulus artifacts are blanked for clarity.

synaptic currents in such experiments was $39 \pm 7 \%(n=5)$. This is consistent with a previous report at the calyx of Held that indicated that release was sensitive to EGTA introduced in the presynaptic terminal (Borst and Sakmann, 1996). We also found that EGTA accelerated the decay of the synaptic current, as is apparent by comparing the normalized synaptic currents in control conditions and after EGTA introduction (Fig. 1B, right). This effect on the time course of the EPSC was interesting because EGTA appeared to be altering the EPSC in a way that was consistent with a reduction in TR. However, the effect was often subtle, and thus it was difficult to exclude contributions from postsynaptic effects such as series resistance errors.

We therefore refined our approach by stimulating the granule cell parallel fibers at an intensity that elicited, on average, $<1.5$ quanta per trial. This enabled us to explore the slow decay phase of the evoked EPSC by resolving the unitary events that constitute the evoked EPSC. We refer to this stimulus as "low-intensity stimulation," because multiple presynaptic inputs are activated, in contrast to "minimal stimulation," in which a single presynaptic input is activated. Ten consecutive trials are shown in Figure $2 A$ to illustrate the response to low-intensity stimulation. As shown in these representative traces, many trials were failures; that is, there were no synaptic events in response to parallel fiber stimulation. In other trials a small number of quanta were evoked with variable latency.

Superimposed quantal events from a single experiment, obtained from trials in which only a single event was detected, are shown in Figure $2 B$. A plot of the amplitude histogram of the quantal events clearly demonstrates that the amplitudes of the quantal events are variable in size and well above the noise threshold for event detection (Fig. 2B, inset). Thus we are confident that we can detect the majority of quantal events elicited by low-intensity stimulation.

The average synaptic current produced by such stimulation is shown in Figure 2C. The EPSC (bold trace) begins $1.9 \mathrm{msec}$ after stimulation and reaches its peak $1.5 \mathrm{msec}$ later. The average quantal event (thin trace) has been scaled to show that the rise and decay times of the quantal events are faster than those of the average evoked EPSC; this is seen more clearly in the semilogarithmic plot of Figure $2 D$. Notably, the decay phase of the EPSC is poorly fit by a single exponential, but it is well approximated by a double exponential decay (Fig. $2 D ; \tau_{\text {fast }}=1.15 \mathrm{msec}$ and $\tau_{\text {slow }}=$ $4.5 \mathrm{msec}) . \tau_{\text {slow }}$ does not reflect a slow decay phase of the quantal event, which returns to $2 \%$ of peak values with a single exponential decay $(\tau=680 \mu \mathrm{sec})$. This is consistent with studies showing that asynchrony of release helps to shape the time course of the synaptic current (Katz and Miledi, 1964; Diamond and Jahr, 1995; Isaacson and Walmsley, 1995).

Superimposed traces from hundreds of trials are displayed on the same time scale as the average synaptic current in Figure 3, $A$ and $B$. We concentrate on the first $20 \mathrm{msec}$ of release, which includes both the phasic and transient release and commonly is taken to correspond to fast synaptic transmission (Goda and Stevens, 1994). A raster plot of the latency of quantal events for each trial shows that the timing of neurotransmitter release is stochastic and reveals that many events occur well after the peak of the ensemble EPSC (Fig. 3C). The latency histogram obtained from the raster plot is a measure of the probability of release (Fig. $3 D)$. For $\sim 3 \mathrm{msec}$ the release rates are high; then they decline but persist above background rates for tens of milliseconds. The cumulative latency histogram (Fig. $3 E$ ), which is the integral of the latency histogram in Figure $3 D$ normalized to the total release in the $20 \mathrm{msec}$ after the onset of the EPSC, provides a convenient way of presenting the fraction of release that has occurred by a given time. As shown in this plot, $\sim 50 \%$ of the total release has occurred before the peak of the EPSC. By $5 \mathrm{msec}$ after the stimulus the synaptic charge has reached $\sim 80 \%$ of the total charge, indicating that the transient tail of release accounts for $\sim 20 \%$ of the total synaptic charge.

Therefore, neurotransmitter release at the granule cell to stellate cell synapse shares many features with release at other synapses (Katz and Miledi, 1964; Diamond and Jahr, 1995; Isaacson and Walmsley, 1995). The asynchrony of release on the milliseconds time scale results in an average evoked EPSC that has a substantially slower rise time and decay time than the average quantal event. More relevant to this study, however, is the presence of a transient tail of release that persists long after the peak of the EPSC. To determine the role of presynaptic calcium in the transient tail of release, we examined the effects of different manipulations of presynaptic calcium on TR. 

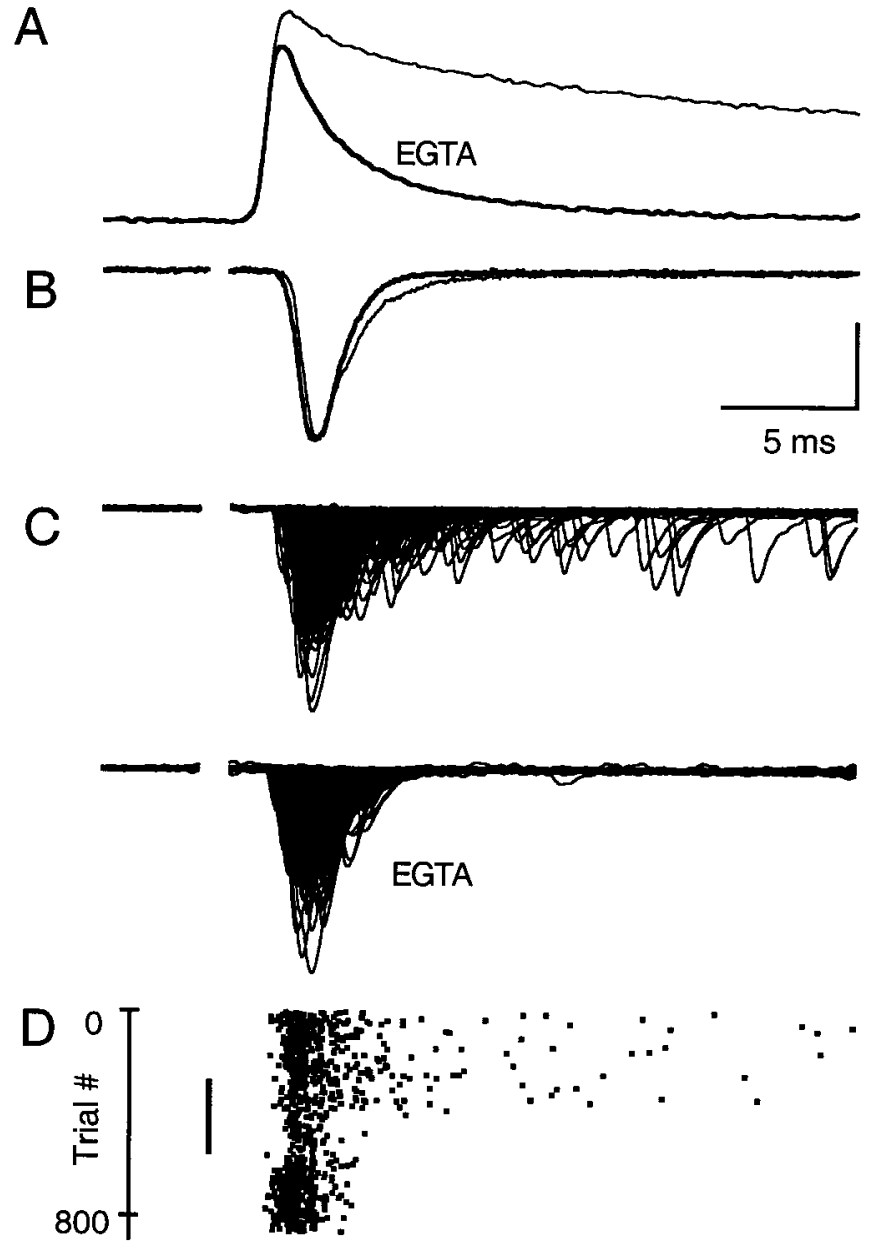

E
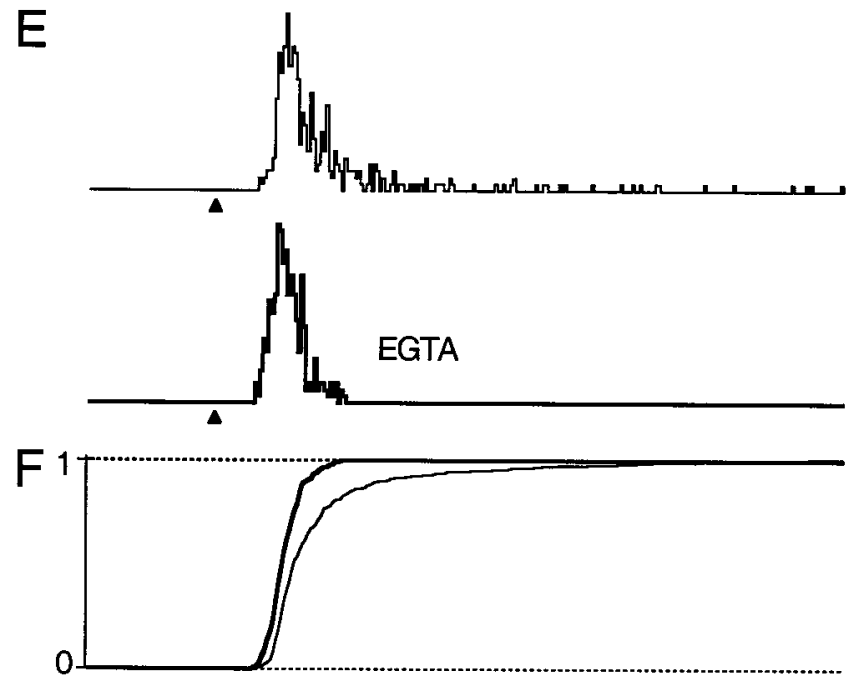

Figure 4. EGTA-AM eliminates late evoked quantal events. $A$, Comparison of magnesium green $\Delta F / F$ signals before (thin trace) and after loading with $100 \mu \mathrm{M}$ EGTA-AM (bold trace) on a fast time scale. $B$, Average EPSCs in control conditions (thin trace) and after EGTA-AM (bold trace). EPSCs are normalized to the respective peak currents. $C$, Superimposed plots of 340 consecutive evoked trials each, recorded in control conditions and after loading with EGTA. $D$, Raster plot of evoked quanta. Stimulus intensity was increased from 19 to $23 \mu \mathrm{A}$ after EGTA-AM application wash-in (black bar) to maintain an average of 0.5-1.5 quanta per trial. $E$, Latency histograms for control conditions and after EGTA-AM application. $F$, Superimposed cumulative latency histograms for control (thin
The effects of EGTA-AM on fast neurotransmitter release

We first studied the effect of EGTA on the time course of evoked synaptic transmission. Figure $4 B$ shows superimposed normalized traces of the average evoked current before (thin trace) and after (bold trace) EGTA introduction. It is clear that EGTA eliminates the transient tail of the EPSC waveform. The decay time course of the EPSC now can be fit with a single exponential $(\tau=1 \mathrm{msec})$. To evaluate the quantal release underlying the EPSC, we superimposed consecutive trials before and after introducing EGTA (Fig. 4C, top and bottom, respectively). EGTA eliminates late quantal events. The raster plot shows that, after loading with EGTA, 99\% of release occurs within a $3 \mathrm{msec}$ interval (Fig. 4D). A comparison of the latency histograms in control conditions and after loading with EGTA-AM reveals that TR has been eliminated (Fig. 4E). Superimposed cumulative latency histograms from the two data sets, normalized to the total release in the $20 \mathrm{msec}$ after the onset of release, show that the EGTA-AM-sensitive transient tail of fast neurotransmitter release comprises $18 \%$ of the total synaptic charge (Fig. $4 F$ ). These effects are not attributable to changes in the time course of the quantal events (control $\tau=700 \mu \mathrm{sec}$; EGTA $\tau=670 \mu \mathrm{sec}$ ) or to changes in the width of the presynaptic volley $(n=3)$. Moreover, high concentrations of EGTA in the recording pipette solution exclude possible postsynaptic effects. Thus, EGTA accelerates $\mathrm{Ca}_{\text {res }}$ decay, which in turn eliminates late release events, thereby speeding the EPSC decay.

\section{The effects of lowering calcium on the timing of fast neurotransmitter release}

Although the most obvious effect of EGTA is to accelerate the decay of $\mathrm{Ca}_{\text {res }}$, it also reduces peak $\Delta F / F$ signals and also may decrease $\mathrm{Ca}_{\text {local }}$. We therefore compared the effects of EGTA with those produced by decreasing external calcium concentration $\left(\mathrm{Ca}_{\mathrm{e}}\right)$. Lowering $\mathrm{Ca}_{\mathrm{e}}$ from 2 to $1 \mathrm{~mm}$ decreased peak $\Delta F / F$ signals without altering the time course of $\mathrm{Ca}_{\text {res }}$ (Fig. $5 A$ ). Given the much larger effect of low $\mathrm{Ca}_{\mathrm{e}}$ on peak $\Delta F / F$ signals $(61 \%$ of control in low $\mathrm{Ca}_{\mathrm{e}}$ as compared with $84 \%$ of control in EGTA), we conclude that $1 \mathrm{~mm} \mathrm{Ca}$ has a much larger effect on $\mathrm{Ca}_{\text {local }}$ than does EGTA. Lowering $\mathrm{Ca}_{\mathrm{e}}$ did not affect the time course of the average EPSC (Fig. 5B). The superimposed trials (Fig. 5C), the raster plot (Fig. $5 D$ ), the release histograms (Fig. $5 E$ ), and the cumulative latency histograms (Fig. $5 F$ ) indicate that the timing of release is not altered in $1 \mathrm{mM} \mathrm{Ca}_{\mathrm{e}}$. Thus, a large decrease in $\mathrm{Ca}_{\text {local }}$ does not affect the time course of release.

\section{Summary comparison of calcium manipulations}

A summary of the time course of neurotransmitter release is shown in Figure 6 for control conditions $(n=15)$, after loading with EGTA $(n=10)$, and in low $\mathrm{Ca}_{\mathrm{e}}(n=5)$. In the lower graphs the traces are superimposed for comparison. Comparison of the cumulative probability histograms demonstrates that the fraction of release that occurs within $3 \mathrm{msec}$ after the onset of release is $80 \pm 1 \%$ for control conditions, $97 \pm 1 \%$ after loading with

$\leftarrow$

line) and EGTA (thick line) data. Calcium measurements $(A)$ and synaptic physiology $(B-F)$ were obtained from two different experiments. All traces are on the same time scale. The relative timing of calcium influx $(A)$ and the evoked EPSCs $(B-F)$ was adjusted according to Sabatini and Regehr (1998). $B-F$ are all aligned to the beginning of the stimulus (arrowhead in $E$ ). Vertical scale bars: $A, 3.4 \% ; B, 20 \mathrm{pA}$ for control and $22.7 \mathrm{pA}$ for EGTA; $C, 100 \mathrm{pA} ; E, 0.04$ events per trial. 

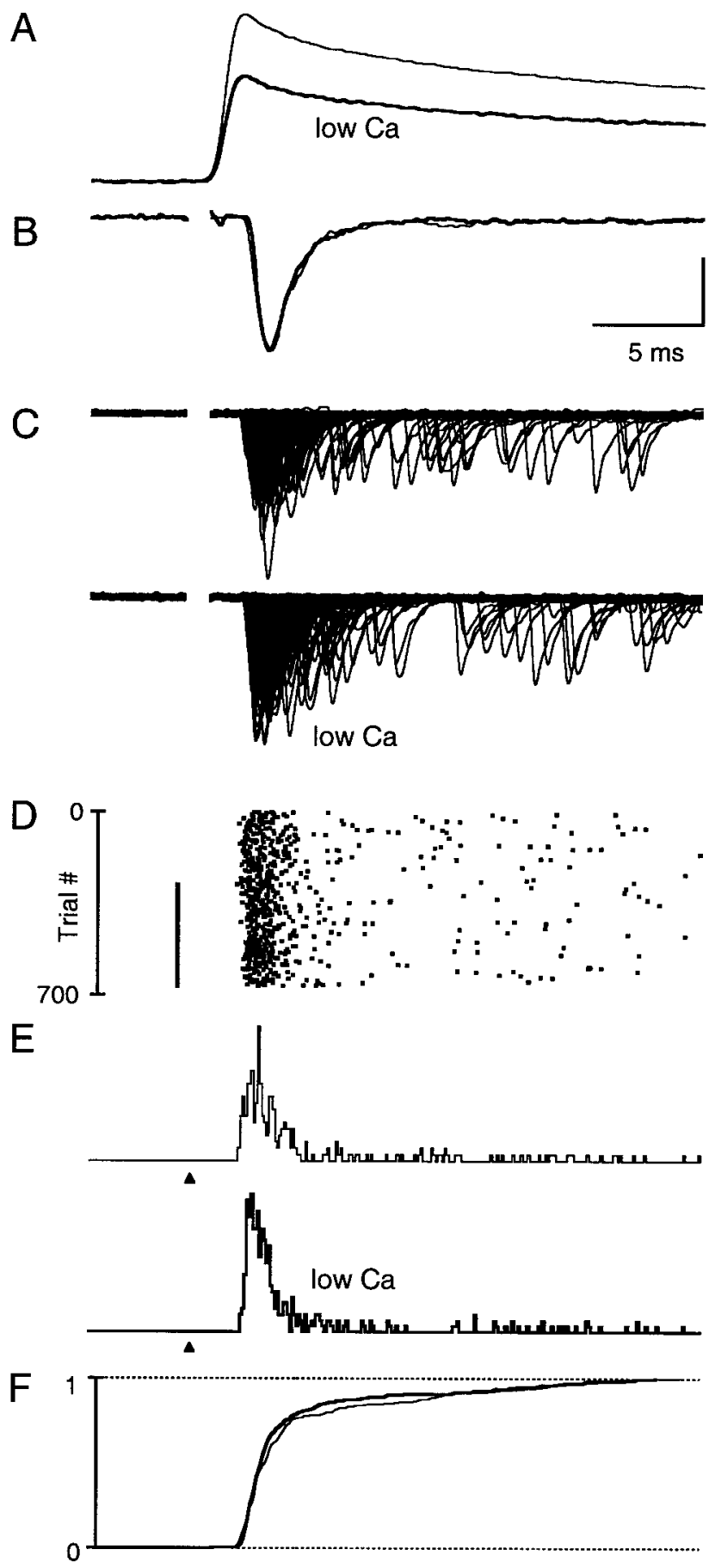

Figure 5. Low external calcium reduces peak calcium levels but does not alter the time course of $\mathrm{Ca}_{\text {res }}$ or neurotransmitter release. $A$, Comparison of magnesium green $\Delta F / F$ signals in $2 \mathrm{mM} \mathrm{Ca}_{\mathrm{e}}$ (thin trace) and $1 \mathrm{mM} \mathrm{Ca}_{\mathrm{e}}$ (bold trace). Each trace is the average of 20 trials. B, Average EPSCs in 2 $\mathrm{mM} \mathrm{Ca}_{\mathrm{e}}$ (thin trace) and in $1 \mathrm{~mm} \mathrm{Ca}_{\mathrm{e}}$ (bold trace). EPSCs are normalized to their respective peak currents. $C$, Plots of 360 consecutive evoked trials each, recorded in $2 \mathrm{mM} \mathrm{Ca}_{\mathrm{e}}$ and in $1 \mathrm{mM} \mathrm{Ca}_{\mathrm{e}} . D$, Raster plot of evoked quanta. Stimulus intensity was increased from 7 to $9 \mu \mathrm{A}$ after switching to $1 \mathrm{mM} \mathrm{Ca}_{\mathrm{e}}$ (indicated by the black bar) to maintain an average of $0.5-1.5$ quanta per trial. $E$, Latency histograms for $2 \mathrm{~mm} \mathrm{Ca}_{\mathrm{e}}$ and $1 \mathrm{~mm} \mathrm{Ca}_{\mathrm{e}} \cdot F$, Superimposed cumulative latency histograms in $2 \mathrm{mM} \mathrm{Ca}_{\mathrm{e}}$ (thin line) and $1 \mathrm{mM} \mathrm{Ca}_{\mathrm{e}}$ (thick line) data. Calcium measurements $(A)$ and synaptic physiology $(B-F)$ were obtained from two different experiments. All traces are on the same time scale as described in Figure 4. Vertical scale bars: $A, 2.4 \% ; B, 8 \mathrm{pA}$ for control and $14.8 \mathrm{pA}$ for low $\mathrm{Ca}_{\mathrm{e}} ; C, 90 \mathrm{pA} ; E$, 0.03 events per trial.
EGTA, and $80 \pm 3 \%$ in low $\mathrm{Ca}_{\mathrm{e}}$ (Fig. $6 A$ ). There is a transient tail of release in control conditions and in low $\mathrm{Ca}_{\mathrm{e}}$, but not after loading with EGTA. This also is seen clearly in the semilogarithmic plots of the time course of release (Fig. 6B). For control conditions and in low $\mathrm{Ca}_{\mathrm{e}}$ the decay phase of release is well approximated by a double exponential $\left(\tau_{\text {fast }} \sim 1 \mathrm{msec}\right.$ and $\tau_{\text {slow }}$ $\sim 10-15 \mathrm{msec}$ ). In contrast, after loading with EGTA, a single exponential $(\tau=640 \mu \mathrm{sec})$ is sufficient to describe the decay phase of release. Thus, $\mathrm{Ca}_{\text {res }}$ plays a significant role in shaping the fast synaptic current by driving a transient tail of release (TR).

\section{The effects of residual calcium at high temperatures}

The experiments described above illustrate a prominent contribution of residual calcium to fast neurotransmitter release. These studies were performed at $24^{\circ} \mathrm{C}$ because of the ease of recording from stellate cells for long times at room temperature (up to $3 \mathrm{hr}$ ). We also performed experiments at $34^{\circ} \mathrm{C}$ to determine whether residual calcium is likely to contribute to the EPSC under more physiological conditions (Fig. 7). As expected, all aspects of synaptic transmission were faster at 34 than at $24^{\circ} \mathrm{C}$. Discrimination of multiple events is more difficult at $34^{\circ} \mathrm{C}$, because release is confined to a very narrow window of time. Consequently, experiments performed at $34^{\circ} \mathrm{C}$ only provide a qualitative description of release. However, the basic effect of EGTA on $\mathrm{Ca}_{\text {res }}$, the evoked EPSC, and the duration of release was qualitatively similar at $34^{\circ} \mathrm{C}(n=5)$ and $24^{\circ} \mathrm{C}$ (compare with Fig. 4). Therefore, the $\mathrm{Ca}_{\text {res }}$-sensitive component of release is likely to be important under physiological conditions.

\section{DISCUSSION}

Our principal finding is that residual calcium plays an important role in synaptic transmission immediately after action potential invasion of presynaptic boutons. Previously, it had been established that $\mathrm{Ca}_{\text {res }}$ was involved in processes on longer time scales, such as facilitation, post-tetanic potentiation, calcium-dependent recovery from depression, and delayed release of neurotransmitter (Stanley, 1986; Magleby, 1987; Delaney et al., 1989; Kandel et al., 1991; Swandulla et al., 1991; Nicholls et al., 1992; Kamiya and Zucker, 1994; Van der Kloot and Molgo, 1994; Zucker, 1994; Atluri and Regehr, 1996; Dittman and Regehr, 1998; Stevens and Wesseling, 1998; Wang and Kaczmarek, 1998). However, it was much more difficult to establish a role for $\mathrm{Ca}_{\text {res }}$ on shorter time scales. Here, by combining low-intensity stimulation to resolve individual quantal events with measurements and manipulations of presynaptic $\mathrm{Ca}_{\text {res }}$, we experimentally demonstrate that $\mathrm{Ca}_{\text {res }}$ controls release just milliseconds after stimulation. Our studies establish that the release we see 3-20 msec after the onset of the EPSC is eliminated by EGTA and is not attributable to a slow process solely triggered by $\mathrm{Ca}_{\text {local }}$.

\section{Implications for the calcium dependence of release}

Our findings have important implications for the calcium dependence of synaptic transmission. Previously, it has been difficult to determine whether $\mathrm{Ca}_{\text {res }}$ can drive release at sufficient rates to contribute to the EPSC. Studies of the calcium dependence of release at goldfish bipolar neurons showed that release is steeply calcium-dependent and that significant release rates are not observed until calcium levels are $10 \mu \mathrm{M}$ (Heidelberger et al., 1994). If we assume that release at granule cell synapses has a similar calcium dependence of release as goldfish bipolar neurons, at first glance there appears to be a fundamental inconsistency. Our results show significant release rates, up to $10 \%$ of peak rates, 


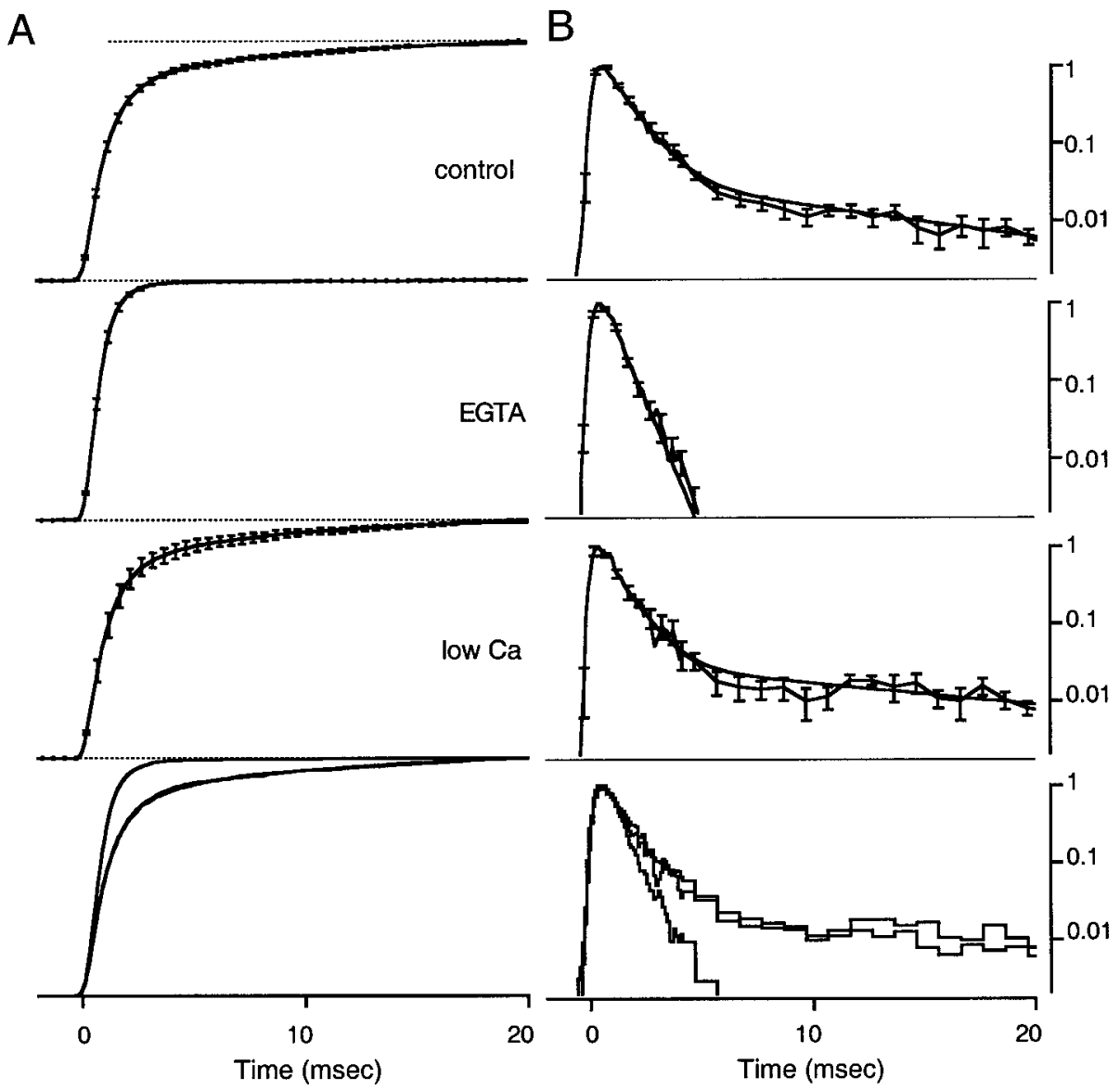

Figure 6. The effects of calcium manipulations on the time course of release. $A$, Summary cumulative probability histograms in control conditions $(n=15)$, after loading with $100 \mu \mathrm{M}$ EGTA-AM $(n=10)$, and in $1 \mathrm{mM} \mathrm{Ca}_{\mathrm{e}}(n=5)$. The dotted horizontal line corresponds to $100 \%$ of the events in the $20 \mathrm{msec}$ after the onset of release. $B$, Semilogarithmic plot of the normalized probability histograms, which are calculated by differentiating the corresponding cumulative probability histogram and normalizing to peak rates of release. In the bottom panel the averaged traces for the three different conditions are superimposed. Error bars represent \pm SEM. Vertical scales are shown on the right of each row. when calcium levels are submicromolar. It is possible, however, to reconcile these results by taking into account our previous studies of delayed release (Atluri and Regehr, 1998). We have shown previously that DR at the granule to stellate cell synapse in the 1 sec after stimulation consists of two components, one steeply dependent on $\mathrm{Ca}_{\text {res }}$ and the other linearly dependent on $\mathrm{Ca}_{\text {res }}$ (Atluri and Regehr, 1998) (see also Fig. 8). The rate of release associated with the linearly dependent component is much too small to account for TR. However, based on similarities in their $\mathrm{Ca}_{\text {res }}$ sensitivities, time courses, and magnitudes, the steeply $\mathrm{Ca}_{\text {res }}$-dependent components of DR and TR appear to share the same mechanism. Our earlier study demonstrated that the steeply $\mathrm{Ca}_{\text {res }}$-dependent component of DR has an interesting feature: $\mathrm{Ca}_{\text {res }}$ is more effective in driving release when it is preceded by a high $\mathrm{Ca}_{\text {local }}$ signal. This feature suggests that, when preceded by $\mathrm{Ca}_{\text {local }}$, submicromolar levels of $\mathrm{Ca}_{\text {res }}$ can trigger the significant rates of release observed in $\mathrm{TR}$, whereas the same concentrations of $\mathrm{Ca}_{\text {res }}$, alone, cannot.

\section{Implications for EGTA sensitivity of transmission at mammalian and squid synapses}

Our findings also help to clarify the differences between the squid giant synapse and synapses in the mammalian CNS in their response to EGTA. The introduction of high concentrations of EGTA presynaptically does not affect synaptic transmission at the squid giant synapse (Adler et al., 1991), whereas a similar concentration of BAPTA profoundly reduces synaptic transmission. The differential effects on transmission of these two calcium chelators are attributed to differences in their kinetics, with BAPTA binding calcium over 100 times faster than EGTA.
These observations indicate that, at the squid giant synapse, release is driven by a very large calcium signal $(>100 \mu \mathrm{M})$ that is highly localized. In contrast, EGTA depresses transmission at the rat calyx of Held (Borst and Sakmann, 1996) and at the granule to stellate cell synapse, indicating that release at these synapses is fundamentally different from in squid. An explanation that accounts for these observations is that, at mammalian synapses, release at single sites is driven by calcium influx through multiple calcium channels; this is referred to as the overlapping domain model (Augustine et al., 1991; Takahashi and Momiyama, 1993; Wu and Saggau, 1994; Mintz et al., 1995; Randall and Tsien, 1995; Borst and Sakmann, 1996). According to this view, some of the calcium channels are sufficiently far from the release site that EGTA can bind calcium before it reaches the release site.

The overlapping domain model can account for the effect of EGTA on peak release, but it does not account for the effect of EGTA on the time course of release. Whether release is driven by single calcium channels or by multiple calcium channels, the $\mathrm{Ca}_{\text {local }}$ that triggers release does not persist long after the calcium channels close (Chad and Eckert, 1984; Fogelson and Zucker, 1985; Simon and Llinás, 1985; Roberts, 1994). Our results demonstrate, however, that a component of release persists well after calcium channels close and $\mathrm{Ca}_{\text {local }}$ has dissipated; this component is driven by $\mathrm{Ca}_{\text {res }}$. Therefore, it is also necessary to consider this

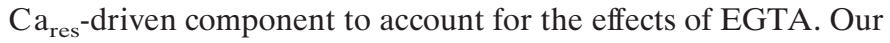
results suggest that differences in $\mathrm{Ca}_{\text {res }}$ at these synapses, combined with the sensitivity of release to $\mathrm{Ca}_{\text {res }}$, also contribute to the differential effects of EGTA in squid and mammalian synapses. After single stimuli the changes in $\mathrm{Ca}_{\text {res }}$ are small at the 

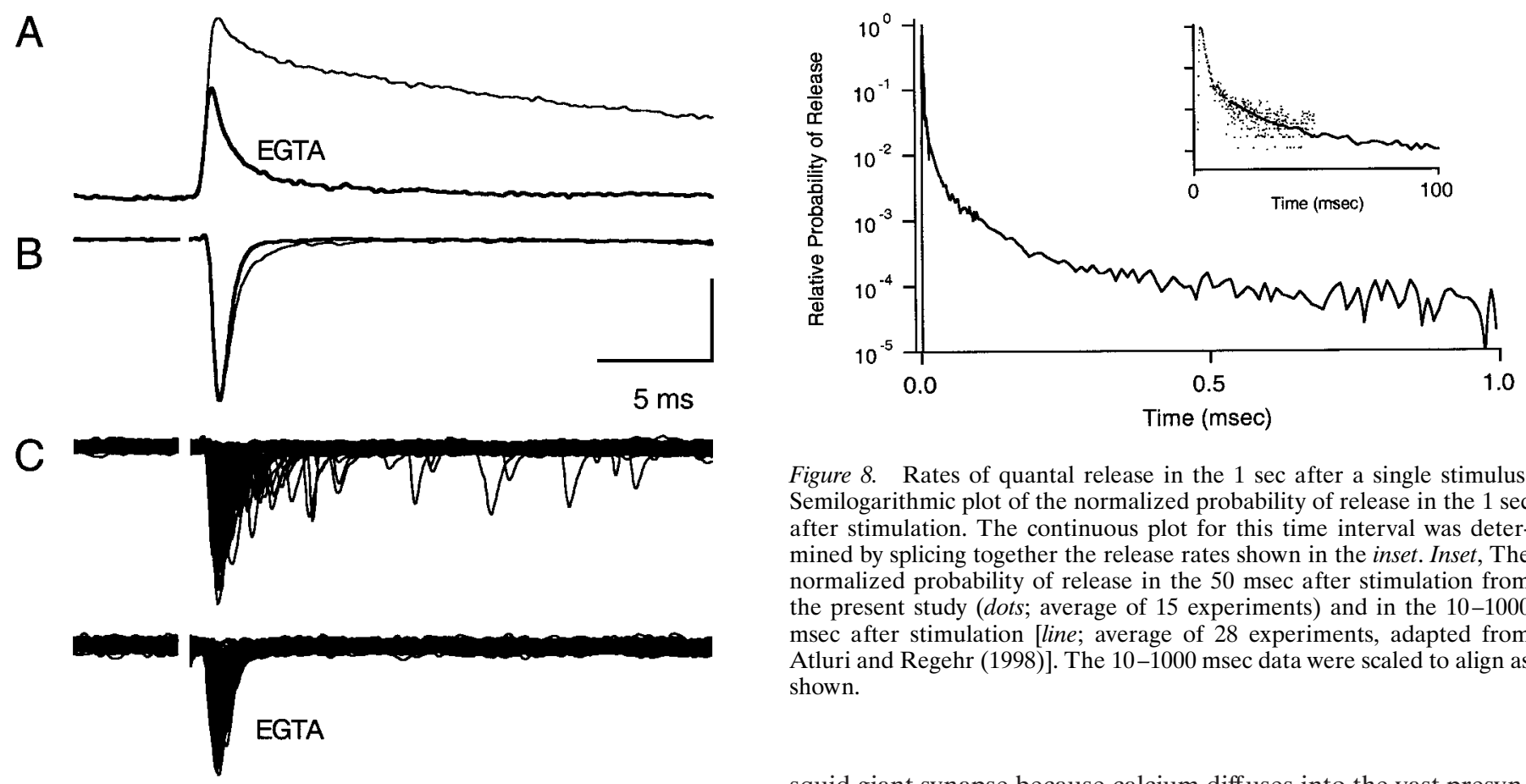

Figure 8. Rates of quantal release in the $1 \mathrm{sec}$ after a single stimulus. Semilogarithmic plot of the normalized probability of release in the $1 \mathrm{sec}$ after stimulation. The continuous plot for this time interval was determined by splicing together the release rates shown in the inset. Inset, The normalized probability of release in the $50 \mathrm{msec}$ after stimulation from the present study (dots; average of 15 experiments) and in the 10-1000 msec after stimulation [line; average of 28 experiments, adapted from Atluri and Regehr (1998)]. The 10-1000 msec data were scaled to align as shown.

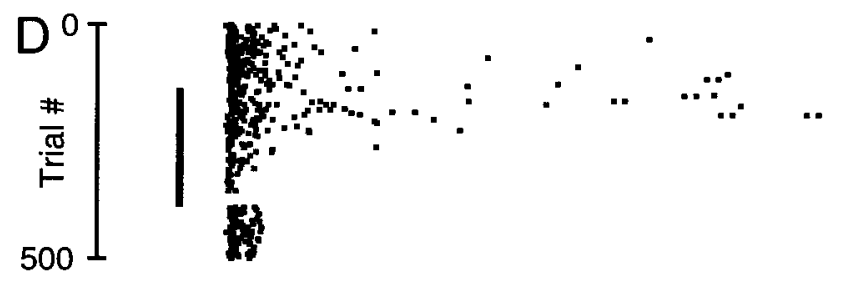

squid giant synapse because calcium diff uses into the vast presynaptic terminal (Smith et al., 1993). In contrast, at the smaller presynaptic boutons of the mammalian $\mathrm{CNS}, \mathrm{Ca}_{\text {res }}$ increases by several hundred nanomolars (Helmchen et al., 1997), a range that we have shown can influence release. Thus we conclude that EGTA sensitivity of release at mammalian synapses arises, in part, from release being driven by overlapping calcium domains and in part by a $\mathrm{Ca}_{\mathrm{res}}$-sensitive component of release that is prominent in mammalian synapses in which $\mathrm{Ca}_{\text {res }}$ is large.

It is likely that $\mathrm{Ca}_{\text {res }}$ also contributes to release on rapid time scales at other synapses in the mammalian CNS. Such synapses generally have a high calcium channel density and small volume (Regehr and Atluri, 1995; Borst and Sakmann, 1996; Helmchen et al., 1997). As a result, stimulus-evoked changes in $\mathrm{Ca}_{\text {res }}$ are several hundred nanomolars, similar to what we estimate for parallel fiber presynaptic boutons.

\section{Physiological significance of residual calcium}

Although the effect on the average synaptic current is subtle, $\mathrm{Ca}_{\text {res}}$-sensitive release is likely to be important under physiological conditions. Although we have focused on the first $20 \mathrm{msec}$ after the onset of release, a time domain relevant to the EPSC, elevated levels of transmitter release continue for hundreds of milliseconds (Atluri and Regehr, 1998). When combined with previous results (Atluri and Regehr, 1998), our findings provide a more complete description of the time course of neurotransmitter release after single stimuli at a mammalian synapse. In the earlier study the focus was on tens to hundreds of milliseconds after stimulation, and very large stimulus intensities were needed to evoke sufficient events for analysis. In contrast, here we use low intensities suited to examine release on short time scales. By combining these results, it is possible to quantify the release rates as a function of time in the $1 \mathrm{sec}$ after stimulation, as shown in Figure 8 . Of the quantal events evoked by single stimuli, $66 \%$ occur within the initial $3 \mathrm{msec}$ interval, and the remaining $34 \%$ of the events occur at later times and require elevated $\mathrm{Ca}_{\text {res }}$. Therefore, we show that $\mathrm{Ca}_{\text {res }}$ drives a significant fraction of 
synaptic charge transfer. Furthermore, although we have concentrated on low-frequency stimulation, the contribution of $\mathrm{Ca}_{\text {res }}$ probably is enhanced during high-frequency trains (10$100 \mathrm{~Hz}$ ) that elevate $\mathrm{Ca}_{\text {res }}$.

\section{REFERENCES}

Adler EM, Augustine JG, Duffy SN, Charlton MP (1991) Alien intracellular calcium chelators attenuate neurotransmitter release at the squid giant synapse. J Neurosci 11:1496-1507.

Atluri PP, Regehr WG (1996) Determinants of the time course of facilitation at the granule cell to Purkinje cell synapse. J Neurosci 16:5661-5671.

Atluri PP, Regehr WG (1998) Delayed release of neurotransmission from cerebellar granule cells. J Neurosci 18:8214-8227.

Augustine GJ, Adler EM, Charlton MP (1991) The calcium signal for transmitter secretion from presynaptic nerve terminals. In: Calcium entry and action at the presynaptic nerve terminal (Stanley EF, Nowycky MC, Triggle DJ, eds), pp 365-381. New York: New York Academy of Sciences.

Barbour B, Keller BU, Llano I, Marty A (1994) Prolonged presence of glutamate during excitatory synaptic transmission to cerebellar Purkinje cells. Neuron 12:1331-1343.

Barrett EF, Stevens CF (1972) The kinetics of transmitter release at the frog neuromuscular junction. J Physiol (Lond) 227:691-708.

Borst JG, Sakmann B (1996) Calcium influx and transmitter release in a fast CNS synapse. Nature 383:431-434.

Chad JE, Eckert R (1984) Calcium domains associated with individual channels can account for anomalous voltage relations of $\mathrm{Ca}$-dependent responses. Biophys J 45:993-999.

Cohen IS, Van der Kloot W (1986) Facilitation and delayed release at single frog neuromuscular junctions. J Neurosci 6:2366-2370.

Cummings DD, Wilcox KS, Dichter MA (1996) Calcium-dependent paired-pulse facilitation of miniature EPSC frequency accompanies depression of EPSCs at hippocampal synapses in culture. J Neurosci 16:5312-5323.

Delaney KR, Zucker RS, Tank DW (1989) Calcium in motor nerve terminals associated with post-tetanic potentiation. J Neurosci 9:3558-3567.

Diamond JS, Jahr CE (1995) Asynchronous release of synaptic vesicles determines the time course of the AMPA receptor-mediated EPSC. Neuron 15:1097-1107.

Dittman JS, Regehr WG (1998) Calcium dependence and recovery kinetics of presynaptic depression at the climbing fiber to Purkinje cell synapse. J Neurosci 18:6147-6162.

Erulkar SD, Rahamimoff R (1978) The role of calcium ions in tetanic and post-tetanic increase of miniature end-plate potential frequency. J Physiol (Lond) 278:501-511.

Feller MB, Delaney KR, Tank DW (1996) Presynaptic calcium dynamics at the frog retinotectal synapse. J Neurophysiol 76:381-400.

Fogelson AL, Zucker RS (1985) Presynaptic calcium diffusion from various arrays of single channels. Implications for transmitter release and synaptic facilitation. Biophys J 48:1003-1017.

Goda Y, Stevens CF (1994) Two components of transmitter release at a central synapse. Proc Natl Acad Sci USA 91:12942-12946.

Heidelberger R, Heinemann C, Neher E, Matthews G (1994) Calcium dependence of the rate of exocytosis in a synaptic terminal. Nature 371:513-515.

Helmchen F, Borst JGG, Sakmann B (1997) Calcium dynamics associated with a single action potential in a CNS presynaptic terminal. Biophys J 72:1458-1471.

Hubbard JI (1963) Repetitive stimulation at the mammalian neuromuscular junction, and the mobilization of transmitter. J Physiol (Lond) 169:641-662.

Isaacson JS, Walmsley B (1995) Counting quanta: direct measurements of transmitter release at a central synapse. Neuron 15:875-884.

Kamiya H, Zucker RS (1994) Residual $\mathrm{Ca}^{2+}$ and short-term synaptic plasticity. Nature 371:603-606.

Kandel ER, Schwartz JH, Jessell TM (1991) Principles of neural science. New York: Elsevier.

Katz B, Miledi R (1964) The measurement of synaptic delay, and the time course of acetylcholine release at the neuromuscular junction. Proc R Soc Lond [Biol] 161:483-495.

Katz B, Miledi R (1965) The effect of temperature on the synaptic delay at the neuromuscular junction. J Physiol (Lond) 181:656-670.

Konnerth A, Llano I, Armstrong CM (1990) Synaptic currents in cerebellar Purkinje cells. Proc Natl Acad Sci USA 87:2662-2665.

Magleby KL (1987) Short-term changes in synaptic efficacy. In: Synaptic function (Edelman GM, Gall WE, Cowan WM, eds), pp 21-56. New York: Wiley.

Matthews G (1996) Neurotransmitter release. Annu Rev Neurosci 19:219-233.

Miledi R, Thies R (1971) Tetanic and post-tetanic rise in frequency of miniature end-plate potentials in low-calcium solutions. J Physiol (Lond) 212:245-257.

Mintz IM, Sabatini BL, Regehr WG (1995) Calcium control of transmitter release at a cerebellar synapse. Neuron 15:675-688.

Naraghi M, Neher E (1997) Linearized buffered $\mathrm{Ca}^{2+}$ diff usion in microdomains and its implications for calculation of $\left[\mathrm{Ca}^{2+}\right]$ at the mouth of a calcium channel. J Neurosci 17:6961-6973.

Nicholls JG, Martin AR, Wallace BG (1992) From neuron to brain: a cellular and molecular approach to the function of the nervous system. Sunderland, MA: Sinauer.

Palay SL, Chan-Palay V (1974) Cerebellar cortex. New York: Springer.

Rahamimoff R, Yaari Y (1973) Delayed release of transmitter at the frog neuromuscular junction. J Physiol (Lond) 228:241-257.

Randall A, Tsien RW (1995) Pharmacological dissection of multiple types of $\mathrm{Ca}^{2+}$ channel currents in rat cerebellar granule cells. J Neurosci 15:2995-3012.

Ravin R, Spira ME, Parnas H, Parnas I (1997) Simultaneous measurement of intracellular $\mathrm{Ca}^{2+}$ and asynchronous transmitter release from the same crayfish bouton. J Physiol (Lond) 501:251-262.

Regehr WG, Atluri PP (1995) Calcium transients in cerebellar granule cell presynaptic terminals. Biophys J 68:2156-2170.

Regehr WG, Tank DW (1991) Selective fura-2 loading of presynaptic terminals and nerve cell processes by local perfusion in mammalian brain slice. J Neurosci Methods 37:111-119.

Roberts WM (1994) Localization of calcium signals by a mobile calcium buffer in frog saccular hair cells. J Neurosci 14:3246-3262.

Roberts WM, Jacobs RA, Hudspeth AJ (1990) Colocalization of ion channels involved in frequency selectivity and synaptic transmission at presynaptic active zones of hair cells. J Neurosci 10:3664-3684.

Sabatini BL, Regehr WG (1998) Optical detection of presynaptic calcium currents. Biophys J 74:1549-1563.

Schweizer FE, Betz H, Augustine GJ (1995) From vesicle docking to endocytosis: intermediate reactions of exocytosis. Neuron 14:689-696.

Simon SM, Llinás RR (1985) Compartmentalization of the submembrane calcium activity during calcium influx and its significance in transmitter release. Biophys J 48:485-498.

Smith PD, Liesegang GW, Berger RL, Czerlinski G, Podolsky RJ (1984) A stopped-flow investigation of calcium ion binding by ethylene glycol bis( $\beta$-aminoethyl ether)- $N, N^{\prime}$-tetraacetic acid. Anal Biochem 143:188-195.

Smith SJ, Buchanan J, Osses LR, Charlton MP, Augustine GJ (1993) The spatial distribution of calcium signals in squid presynaptic terminals. J Physiol (Lond) 472:573-593.

Stanley EF (1986) Decline in calcium cooperativity as the basis of facilitation at the squid giant synapse. J Neurosci 6:782-789.

Stevens CF, Wesseling JF (1998) Activity-dependent modulation of the rate at which synaptic vesicles become available to undergo exocytosis. Neuron 21:415-424.

Swandulla D, Hans M, Zipser K, Augustine GJ (1991) Role of residual calcium in synaptic depression and post-tetanic potentiation: fast and slow calcium signaling in nerve terminals. Neuron 7:915-926.

Takahashi T, Momiyama A (1993) Different types of calcium channels mediate central synaptic transmission. Nature 366:156-158.

Van der Kloot W (1988) Estimating the timing of quantal release during end-plate currents at the frog neuromuscular junction. J Physiol (Lond) 402:595-603.

Van der Kloot W, Molgo J (1993) Facilitation and delayed release at about $0^{\circ} \mathrm{C}$ at the frog neuromuscular junction: effects of calcium chelators, calcium transport inhibitors, and okadaic acid. J Neurophysiol 69:717-729. 
Van der Kloot W, Molgo J (1994) Quantal acetylcholine release at the vertebrate neuromuscular junction. Physiol Rev 74:899-991.

Wang L-Y, Kaczmarek LK (1998) High-frequency firing helps replenish the readily releasable pool of synaptic vesicles. Nature 394:384-388.

Winslow JL, Duffy SN, Charlton MP (1994) Homosynaptic facilitation of transmitter release in crayfish is not affected by mobile calcium chelators: implications for the residual ionized calcium hypothesis from electrophysiological and computational analyses. J Neurophysiol 72:1769-1793.

Wu L-G, Saggau P (1994) Pharmacological identification of two types of presynaptic voltage-dependent calcium channels at CA3-CA1 synapses of the hippocampus. J Neurosci 14:5613-5622.
Zengel JE, Magleby KL (1981) Changes in miniature endplate potential frequency during repetitive nerve stimulation in the presence of $\mathrm{Ca}^{2+}$, $\mathrm{Ba}^{2+}$, and $\mathrm{Sr}^{2+}$ at the frog neuromuscular junction. J Gen Physiol 77:503-529.

Zhao M, Hollingworth S, Baylor SM (1996) Properties of tri- and tetracarboxylate $\mathrm{Ca}^{2+}$ indicators in frog skeletal muscle fibers. Biophys $\mathrm{J}$ 70:896-916.

Zucker RS (1994) Calcium, short-term synaptic plasticity. Biomed Res 15[Suppl 1]:1-5.

Zucker RS, Lara-Estrella LO (1983) Post-tetanic decay of evoked and spontaneous transmitter release and a residual-calcium model of synaptic facilitation at crayfish neuromuscular junctions. J Gen Physiol $81: 355-372$. 